\title{
INFLUENCE OF LASER PROCESSING ON THE MICROSTRUCTURE, MICROHARDNESS AND CORROSION RESISTANCE OF DIFFUSION BORONIZED LAYER PRODUCED ON $145 \mathrm{Cr} 6$ TOOL STEEL
}

\author{
${ }^{1}$ Aneta BARTKOWSKA, ${ }^{2}$ Dariusz BARTKOWSKI, ${ }^{3}$ Peter JURČI, ${ }^{2}$ Damian PRZESTACKI \\ ${ }^{1}$ Poznan University of Technology, Faculty of Materials Engineering and Technical Physics, Poznan, \\ Poland, EU, aneta.bartkowska@put.poznan.pl \\ ${ }^{2}$ Poznan University of Technology, Faculty of Mechanical Engineering, Poznan, Poland, EU, \\ dariusz.bartkowski@put.poznan.pl,damian.przestacki@put.poznan.pl
}

${ }^{3}$ Slovak University of Technology in Bratislava, Faculty of Materials Science and Technology in Trnava, Trnava Slovakia, EU, p.jurci@stuba.sk

https://doi.org/10.37904/metal.2020.3561

\begin{abstract}
The paper presents the results of laser processing of diffusion boronized layer on $145 \mathrm{Cr} 6$ tool steel. The aim of the study was to investigate the microstructure, phase composition analysis, microhardness as well as corrosion resistance of the newly-formed layer. Boronized layer was produced at $950{ }^{\circ} \mathrm{C}$ by $6 \mathrm{~h}$ in mixture consisted of boron carbide $\mathrm{B}_{4} \mathrm{C}$ as a source of boron, kaolin as a filler and ammonium chloride as activator. Laser processing were conducted using $3 \mathrm{~kW}$ diode laser. As a result of influence the laser beam on the boronized layers the presence of three areas was observed: remelted zone, heat affected zone and substrate. The boronized layers after laser processing were characterized by high microhardness and good corrosion resistance. The zone enrich in boron was a 2-3 times thicker than diffusion boronized layer.
\end{abstract}

Keywords: Boronized layer, laser processing, microstructure, microhardness, corrosion resistance

\section{INTRODUCTION}

One method of saturating the steel surface to improve its mechanical and operation properties is the diffusion boronizing process [1]. As a result of this process, a layer with very good properties such as high microhardness, good wear and corrosion resistance may be obtained [1-4]. Due to the needle-like microstructure, the boronized layer is characterized by good bonding with the steel substrate. However, despite these numerous advantages, the boronized layers are quite fragile. This disadvantage can be manifested by spalling and peeling from the substrate [1]. Therefore, there are many methods to modify this kind of layers [5-8]. One of them is the laser processing of diffusion boronized layer, which consists in the interaction of the laser beam on previously formed iron borides [6,7]. A layer with changed microstructure and new properties is obtained in this way. There are many publications focused on this problem, but most of them concern the modification of layer produced on low $[1,5]$ or medium $[3,6]$ carbon steel. There are few publications about laser processing of diffusion boronized layers produced on high-carbon steels $[2,4,7]$.

The aim of this study was to investigate the influence of laser processing parameters on the microstructure, microhardness and corrosion resistance of diffusion boronized layer produced on $145 \mathrm{Cr} 6 \mathrm{high}$ carbon steel.

\section{METHODOLOGY OF RESEARCH}

The study was conducted on $145 \mathrm{Cr} 6$ tool steel. The chemical composition os steel used is shown in Table 1. Boronized layers was produced at $950^{\circ} \mathrm{C}$ temperature by $6 \mathrm{~h}$ using the furnace with open retort. The boronized mixture consisted of boron carbide B4C as a source of boron, kaolin as a filler and ammonium chloride as 
activator. After diffusion boronizing process, the specimens have been cooled down, then cleaned of powder residue, next degreased in acetone and finally forwarded for further laser processing. Scheme of the furnace with open retort to produce diffusion layers is shown in (Figure 1a). It is composed of: heat resisting steel retort (1), in which are placed specimens (6), powder mixture to boronizing process (2), furnace (3) with a heating elements (4) and thermocouple to the temperature control during process (5).

Table 1 Chemical composition of $145 \mathrm{Cr} 6$ tool steel [\%wt.]

\begin{tabular}{|c|c|c|c|c|c|c|}
\hline $\mathbf{C}$ & $\mathbf{M n}$ & $\mathbf{S i}$ & $\mathbf{P}$ & $\mathbf{S}$ & $\mathbf{C r}$ & $\mathbf{V}$ \\
\hline 1.40 & 0.55 & 0.29 & 0.028 & 0.025 & 1.60 & 0.10 \\
\hline
\end{tabular}

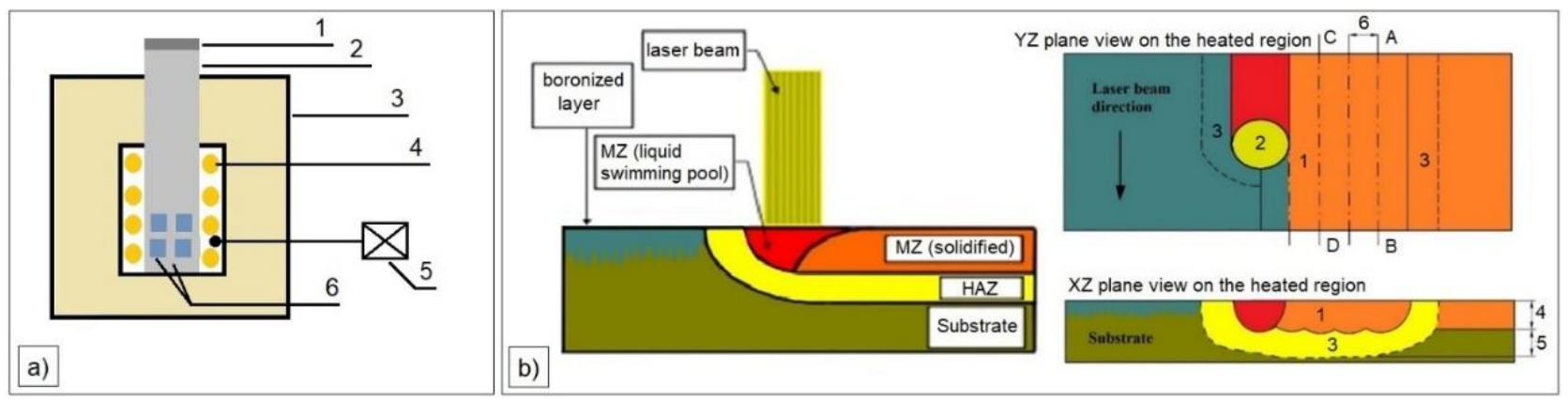

Figure 1 a) View of specimens preparation methodology for diffusion boronizing process, b) flowchart of laser processing of boronized surface layer $1-M Z, 2$ - laser beam, $3-H A Z, 4-$ depth of $M Z, 5-$ depth of HAZ, 6 - overlap

The scheme of laser processing of boronized layer by using laser beam is presented in (Figure 1b). Laser processing was carried out using Trumpf TruDiode 3006 diode laser of nominal power of $3.0 \mathrm{~kW}$ which was integrated with KUKA KR16-2 robot. Parameters used in the experiment were: laser beam power density (q): $76 \mathrm{~kW} / \mathrm{cm}^{2}, 115 \mathrm{~kW} / \mathrm{cm}^{2}, 153 \mathrm{~kW} / \mathrm{cm}^{2}$, laser beam diameter $\mathrm{d}=1 \mathrm{~mm}$ with a mode TEM00 as well as constant scanning laser beam rate $v=3 \mathrm{~m} / \mathrm{min}$. Laser tracks were arranged with distance $f=0.5 \mathrm{~mm}$, where $\mathrm{f}$ was distance between axes of each tracks (Figure 1b). The overlapping of lase tracks was $50 \%$. During the laser processing the laser beam moved from point $A$ to $B$, then laser beam was turn off and laser head returned to point $A$. In the next step the laser beam was transferred by a distance of $0.5 \mathrm{~mm}$ and laser track were made from point $C$ to $D$. This was repeated until the laser processed the entire surface of specimen. As a result of this procedure, characteristic areas of the remelted zone (MZ) and heat affected zone (HAZ) presented in (Figure 1b) were obtained. Microstructure observations were carried out using Huvitz HRM-300 light microscope on cross-sections of specimens prepared by polished and etched in $2 \% \mathrm{HNO} 3$ solution. The phase analysis was performed on EMPYREAN PANalytical X-Ray diffractometer using Cu Ka radiation with the angle range from $20^{\circ}$ to $90^{\circ}$. Microhardness profiles were determined using an FM-810 Vickers microhardness tester equipped with FT-Zero automatic indentation measuring software from Future-Tech. The indentation load was $100 \mathrm{G}$ (HV0.1) and loading time was $15 \mathrm{~s}$. Corrosion resistance were carried out using ATLAS 1131 EU\&IA device. Anodic polarization curves were measured using AtlasCorr05 software. The potentiodynamic polarization tests were performed in a $5 \% \mathrm{NaCl}$ aqueous solution at $22^{\circ} \mathrm{C}$ with scanning rate of $0.5 \mathrm{mV} / \mathrm{h}$. During the corrosion tests the reference electrode was a saturated calomel electrode and the auxiliary electrode was a platinum electrode. The investigation was conducted according with PN-EN ISO 17475 standard.

\section{RESULTS AND DISCUSSION}

Figure 2 shows the microstructure of diffusion boronized layer formed on $145 \mathrm{Cr} 6$ tool steel. The boronized layer has a needle-like microstructure under which chromium carbides are placed characteristic for this steel 
grade. The obtained layer was uniform and oriented perpendicular to the surface of specimen as well as characterized by good cohesion with steel substrate. The average thickness of diffusion boronized layer was $105 \mu \mathrm{m}$. However, in the subsurface zone, the porosity were detected. Authors of this study suggest to remove them using laser processing.

Figure 2 Microstructure of diffusion boronizing layer produced on $145 \mathrm{Cr} 6$ tool steel

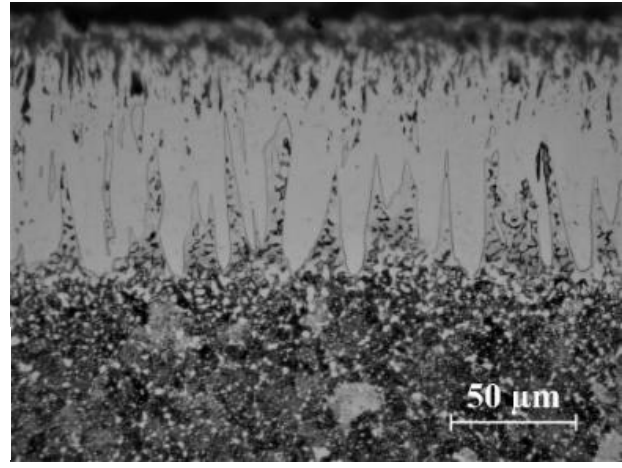

Figure 3 shows the microstructure after laser processing of the boronized layer at the variable laser beam power densities. The obtaining layers was metallurgicaly bonded to the steel substrate and consisted of two characteristic zones. The first was remelted zone (MZ), which was formed as a result of remelting the diffusion boronized layer with the steel substrate. Below, was the heat affected zone (HAZ), which was formed as a result of hardening the substrate material. The remelted zone in each of the analyzed cases consists of boronmartensite eutectics whose contribution depends on the laser processing parameters used. Whereas in the heat affected zone, two areas can be distinguished with different etching color in microstructure. Brighter area (HAZ 1) is the austenitized region. This region transforms to martensite during rapid cooling (darker area marked as HAZ 2). In paper [9] the authors found that by used various laser beam powers the microstructure of HAZ was composed of two different regions. This is the martensite region and the partially-transformed region composed of proeutectoid ferrite, untransformed pearlite and martensite. On the other hand at work [10] the authors found that the hardened zone has a mixed microstructure of martensite and tempered bainite. The steel substrate has not previously subjected to heat treatment, to enable possible to observe changes related to the interaction of the laser beam. The depth dimensions of remelted zone and heat affected zone for individual laser tracks after laser processing of diffusion boronized layers are presented in Table 2. It could be concluded that increasing laser beam power density have an influence both on increased of laser track dimension, depth of remelted zone as well as on heat affected zone. Laser tracks overlapped as can be seen in (Figures $\mathbf{3 a}, \mathbf{3 b}, \mathbf{3 c}$ ). Figures $\mathbf{3 d}, \mathbf{3} \mathbf{e}, \mathbf{3} \mathbf{f}$ are presents selected areas of remelted zone. Figure $\mathbf{3 d}$ presents characteristic dendrites type I and type II which arise due to solidification of melting pool in remelted zone. The character of dendrite solidification shows directions of heat dissipation in the newly formed microstructure. The direction of dendrite growth is from the bottom of laser track (Figure 3e) to its central region.

Table 2 Depth $[\mu \mathrm{m}]$ of boronized layer after laser processing depending on laser beam power density

\begin{tabular}{|c|c|c|c|c|c|c|c|c|c|}
\hline \multirow[t]{2}{*}{ Number of measurement } & \multicolumn{3}{|c|}{$75\left[\mathrm{~kW} / \mathrm{cm}^{2}\right]$} & \multicolumn{3}{|c|}{$115\left[\mathrm{~kW} / \mathrm{cm}^{2}\right]$} & \multicolumn{3}{|c|}{$150\left[\mathrm{~kW} / \mathrm{cm}^{2}\right]$} \\
\hline & MZ & HAZ 1 & HAZ 2 & MZ & HAZ 1 & HAZ 2 & MZ & HAZ 1 & HAZ 2 \\
\hline 1 & 271 & 42 & 59 & 426 & 45 & 77 & 518 & 72 & 102 \\
\hline 2 & 269 & 44 & 62 & 416 & 51 & 83 & 512 & 75 & 107 \\
\hline 3 & 264 & 46 & 61 & 422 & 46 & 79 & 522 & 73 & 102 \\
\hline 4 & 265 & 42 & 64 & 413 & 53 & 85 & 517 & 75 & 105 \\
\hline 5 & 258 & 45 & 64 & 420 & 47 & 81 & 524 & 73 & 104 \\
\hline average & 265 & 44 & 62 & 419 & 48 & 81 & 519 & 74 & 104 \\
\hline total thickness $[\mu \mathrm{m}]$ & \multicolumn{3}{|c|}{371} & \multicolumn{3}{|c|}{548} & \multicolumn{3}{|c|}{697} \\
\hline
\end{tabular}

At low laser beam power density, cracks in the remelted zone are visible (Figure 3a). They are reveal when the heat dissipation rate is relatively fast, and the material solidifies very quickly. The increase of laser beam 
power density caused increase in heat which resulted in slower heat dissipation in the material, and thus contributes to obtained the layers free of cracks. The boronized layers before and after laser processing were analyzed using XRD method, and results are shown in (Figure 4). In the diffusion boronized layer the iron boride equilibrium phases ( $\mathrm{FeB}$ and $\mathrm{Fe}_{2} \mathrm{~B}$ ) were detected. The $\mathrm{FeB}$ phase peak intensity was significant. After laser processing of boronized layers equilibrium iron boride phase $\mathrm{FeB}$ and $\mathrm{Fe}_{2} \mathrm{~B}$, non-equilibrium $\mathrm{Fe}_{3} \mathrm{~B}$ as well as iron phase were detected. The peak intensity of iron boride phases $\mathrm{FeB}$ and $\mathrm{Fe}_{2} \mathrm{~B}$ decreases when the laser tracks are deeper and when are produced at higher power density $\left(q=153 \mathrm{~kW} / \mathrm{cm}^{2}\right)$. However, the decrease of laser beam power caused increase of intensity of the non-equilibrium $\mathrm{Fe}_{3} \mathrm{~B}$ iron boride phase.
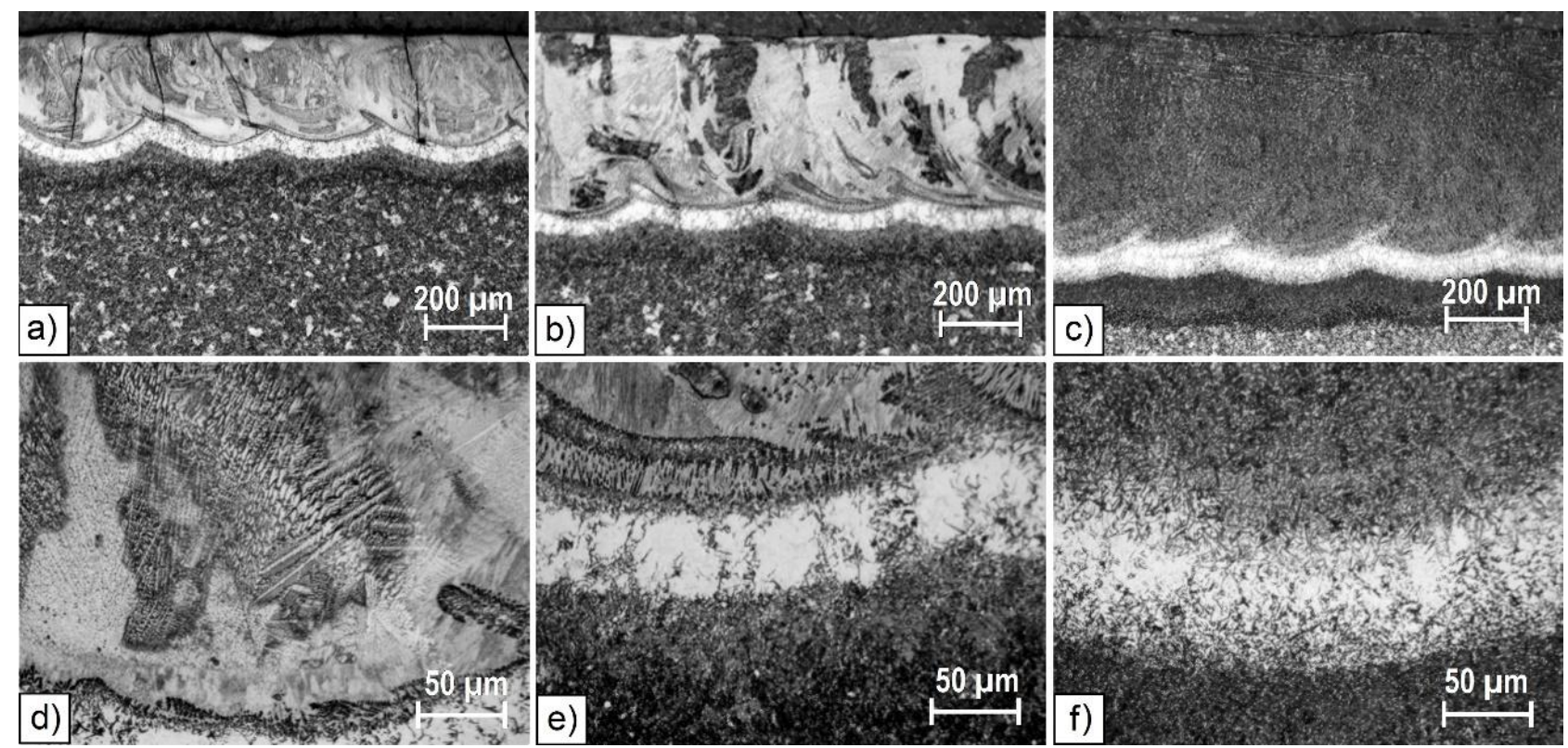

Figure 3 Microstructure after laser processing of boronized layer; $q=76 \mathrm{~kW} / \mathrm{cm}^{2}(a, d), q=76 \mathrm{~kW} / \mathrm{cm}^{2}(b, e)$, $q=153 \mathrm{~kW} / \mathrm{cm}^{2}(\mathrm{c}, \mathrm{f})$

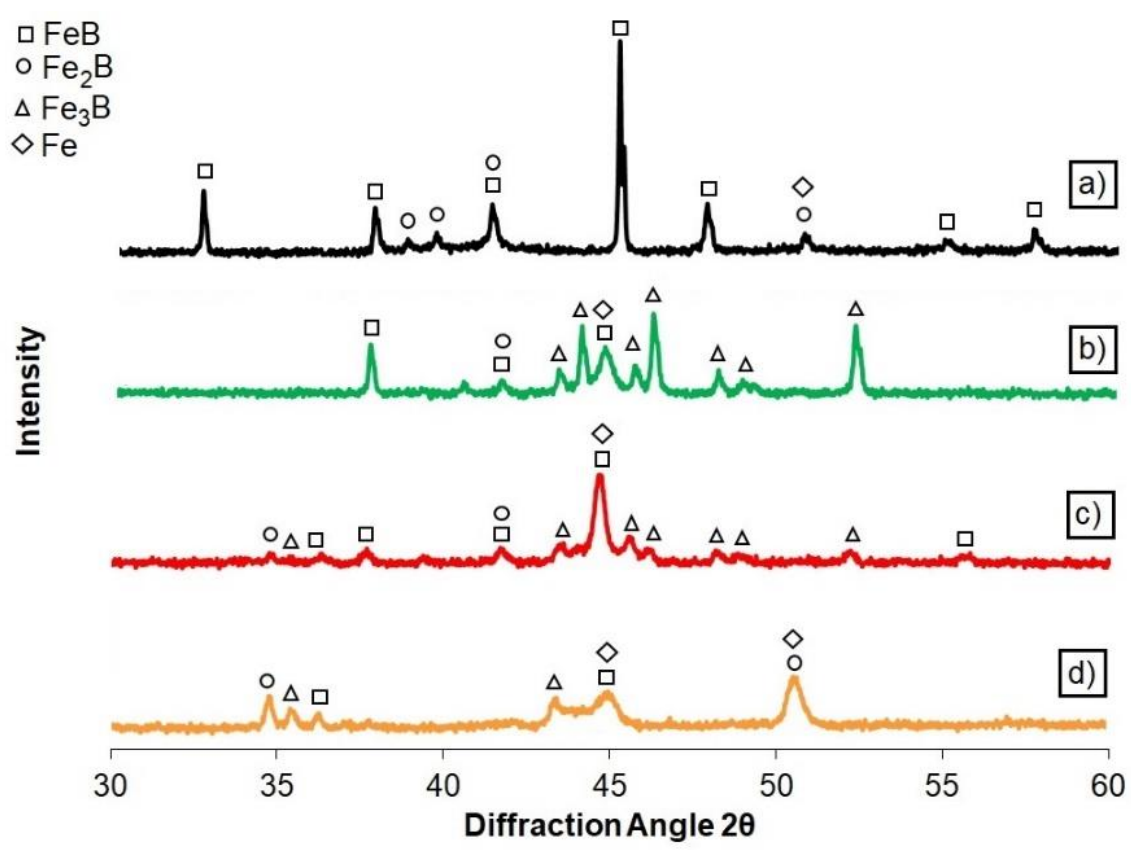

Figure $4 \mathrm{X}$-ray pattern of boronized (a) and boronized layers after laser processing; $q=76 \mathrm{~kW} / \mathrm{cm}^{2}$

(b), $q=115 \mathrm{~kW} / \mathrm{cm}^{2}(\mathrm{c}), \mathrm{q}=153 \mathrm{~kW} / \mathrm{cm}^{2}(\mathrm{~d})$ 
Figure 5 shows the profiles of microhardness of diffusion boronizing layers as well as after laser processing of these layers. Microhardness of boronized layer was about $1800 \mathrm{HV}$ in the FeB iron boride zone and decreases to approx. $1600 \mathrm{HV}-1400 \mathrm{HV}$ in the $\mathrm{Fe}_{2} \mathrm{~B}$ iron boride zone. Microhardness of the substrate was approx. 200 HV (Figure 5a). On the graphs in (Figures 5b, 5c, 5d) were marked the depth of remelted zone and heat affected zone of laser tracks. It may be seen that the laser processing parameters significantly influence on the microstructure and consequently on the microhardness of laser tracks. Figure $\mathbf{5 b}$ shows the profile of microhardness of boronized layer after laser processing at low laser beam power density. The microhardness of the remelted zone was approx. $1200 \mathrm{HV}-1100 \mathrm{HV}$. In this case the microhardness decreases to $700 \mathrm{HV}$ in heat affected zone and next reaches $200 \mathrm{HV}$ in steel substrate. Increased laser beam power density causes decrease microhardness in the remelted zone from about $1000 \mathrm{HV}$ (for $\mathrm{q}=115 \mathrm{~kW} / \mathrm{cm}^{2}$ ) to $900 \mathrm{HV}$ (for $\mathrm{q}=153 \mathrm{~kW} / \mathrm{cm}^{2}$ ). In all the studied specimens the microhardness profiles gradually decrease from remelted zone through heat affected zone to the substrate (Figures $\mathbf{5 b}, \mathbf{5 c}, \mathbf{5 d}$ ).
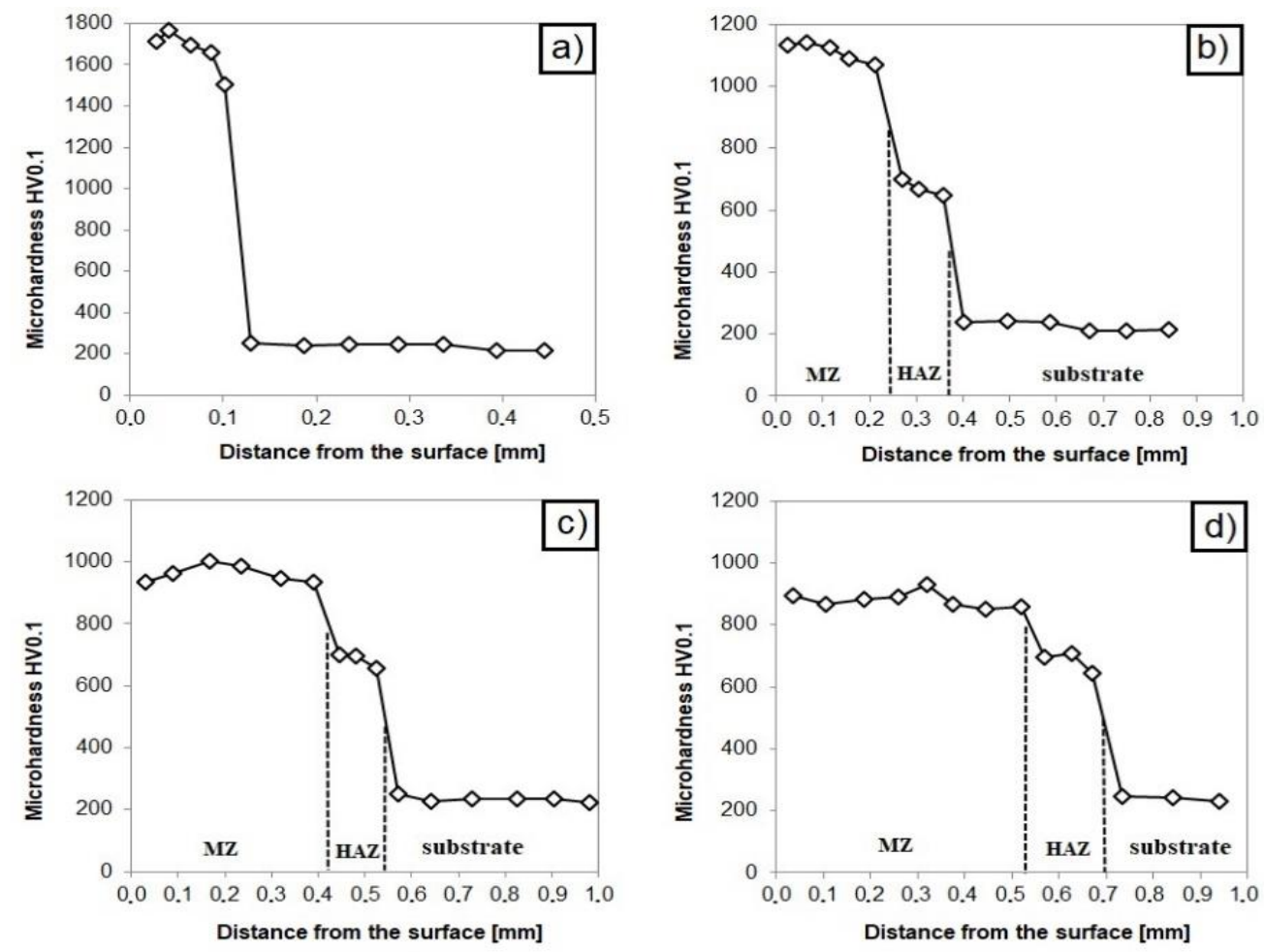

Figure 5 Microhardness profiles of diffusion boronized layer (a) and boronized layers after laser processing;

$$
\mathrm{q}=76 \mathrm{~kW} / \mathrm{cm}^{2}(\mathrm{~b}), \mathrm{q}=115 \mathrm{~kW} / \mathrm{cm}^{2}(\mathrm{c}), \mathrm{q}=153 \mathrm{~kW} / \mathrm{cm}^{2}(\mathrm{~d})
$$

Table 3 Corrosion parameters of diffusion boronized layer before and after laser processing

\begin{tabular}{|c|c|c|}
\hline Specimen & Corrosion current I $\left[\mathbf{A} \cdot \mathbf{c m}^{2}\right]$ & Corrosion potential E [V] \\
\hline B & $3.93 \mathrm{E}-06$ & $-8.56 \mathrm{E}-01$ \\
\hline $\mathrm{B} \& \mathrm{LHT} ; \mathrm{q}=76 \mathrm{~kW} / \mathrm{cm}^{2}$ & $1.23 \mathrm{E}-06$ & $-9.43 \mathrm{E}-01$ \\
\hline $\mathrm{B} \& \mathrm{LHT} ; \mathrm{q}=115 \mathrm{~kW} / \mathrm{cm}^{2}$ & $9.18 \mathrm{E}-07$ & $-8.56 \mathrm{E}-01$ \\
\hline $\mathrm{B} \& \mathrm{LHT} ; \mathrm{q}=153 \mathrm{~kW} / \mathrm{cm}^{2}$ & $1.09 \mathrm{E}-05$ & $-1.07 \mathrm{E}+00$ \\
\hline
\end{tabular}

Results of corrosion resistance tests are presented in (Figure 6) and Table 3. Studies have shown that the diffusion boronized layer has a higher corrosion resistance than most boronized layers subjected laser processing. In the case of a higher laser beam power density $\left(q=153 \mathrm{~kW} / \mathrm{cm}^{2}\right)$ a newly formed surface layer was deeper than a diffusion boronized layer and was characterized by worse corrosion resistance. It was 
caused of larger iron participation from the substrate. A slightly worse corrosion resistance was found for specimen produced using the lowest laser beam power density. In microstructure of this layer many cracks were visible, and those cracks were privileged places for progressive rapid corrosion. The specimen after laser processing using medium laser beam power density $\left(115 \mathrm{~kW} / \mathrm{cm}^{2}\right)$ was characterized by better corrosion resistance than specimen produced using diffusion boronizing (Figure 6).

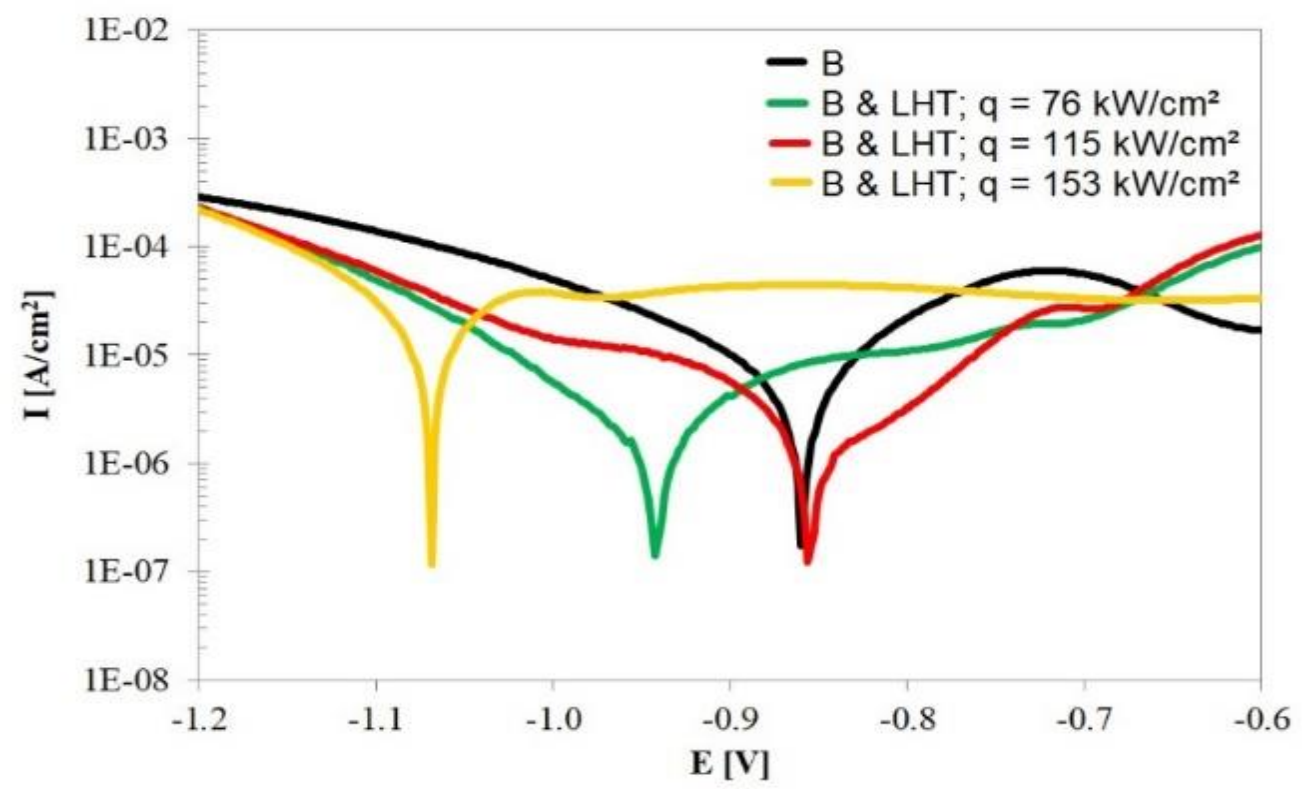

Figure 6 Corrosion resistance curves of diffusion boronized layer before and after laser processing

\section{CONCLUSION}

The following concluding remarks can be made:

1) As a result of laser processing, the needle-like microstructure of diffusion boronized layer was melted. New zone composed of boride-martensitic eutectics was obtained. The equilibrium $\left(\mathrm{FeB}, \mathrm{Fe}_{2} \mathrm{~B}\right)$ and non-equilibrium $\left(\mathrm{Fe}_{3} \mathrm{~B}\right)$ iron borides phases were identified.

2) Boronized layers after laser processing are characterized by a milder gradient microhardness from the surface to the substrate due to presence the heat affected zone. In remelted zone the microhardness was from $1200 \mathrm{HV}$ to $900 \mathrm{HV}$. This depend on the laser processing parameters used.

3) Laser processing at medium laser beam power density caused increase of corrosion resistance of boronized layers in comparison to one without laser modification.

\section{ACKNOWLEDGEMENTS}

\section{Presented work has been financed by the Ministry of Science \& Higher Education in Poland in 2020} year under Project No 0513/SBAD/4607.

\section{REFERENCES}

[1] KRUKOVICH, M.G., PRUSAKOV, B.A., SIZOV, I.G. Plasticity of Boronized Layers, Springer Series in Materials Science, 2016 vol. 237, ISBN 978-3-319-40012-9 (eBook)

[2] MUHAMMAD, W. Boriding of high carbon high chromium cold work tool steel. Mater. Sci. Eng., 2014, vol. 60, pp. $1-6$.

[3] CALIK, A., SIMSEK, M., KARAKAS, M.S., UCAR, N. Effect of boronizing on microhardness and wear resistance of steel AISI 1050 and chilled cast iron. Met. Sci. Heat Treat., 2014, vol. 56, pp. $89-92$. 
[4] JURČl, P., HUDÁKOVÁ, M. Diffusion boronizing of H11 hot work tool steel. J. Mater. Eng. Perform., 2011, vol. 20, pp. 1180-1187.

[5] BALANDIN, Yu.A. Surface hardening of die steel by diffusion boronizing, borocopperizing and borochromizing in fluidized bed. Met. Sci. Heat Treat., 2005, vol. 47, pp. 103-106.

[6] BARTKOWSKA, A., PERTEK, A. Laser production of B-Ni complex layers. Surf. Coat. Technol., 2014, vol. 248, pp. 23-29.

[7] BARTKOWSKA, A., SWADŹBA, R., POPŁAWSKI, M., BARTKOWSKI, D. Microstructure, microhardness, phase analysis and chemical composition of laser remelted FeB-Fe 2 B surface layers produced on Vanadis- 6 steel. Opt Laser Technol. 2016, vol. 86, pp. 115-125.

[8] SAFONOV, A. N. Special features of boronizing iron and steel using a continuous-wave $\mathrm{CO}_{2}$ laser. Met. Sci. Heat Treat., 1998, vol. 40, no.1 - 2, pp. $6-10$.

[9] FERNANDES DE LIMA, M.S., GOIA, F.A. RIVA, R., ESPÍRITO SANTO, A.M. Laser Surface Remelting and Hardening of an Automotive Shaft Sing a High-power Fiber Laser. Materials Research, 2007, vol. 10, no. 4, 461467.

[10] BABU, P.D., BUVANASHEKARAN, G., BALASUBRAMANIAN, K.R. Experimental studies on the microstructure and hardness of laser transformation hardening of lowalloy steel. Transactions of the Canadian Society for Mechanical Engineering, 2012, vol. 36, no. 3, 241-258. 